\title{
Predicting the spread of nuclear radiation from the damaged Fukushima Nuclear Power Plant
}

\author{
QIAO FangLi*, WANG GuanSuo, ZHAO Wei, ZHAO JieChen, DAI DeJun, SONG YaJuan \& \\ SONG ZhenYa
}

First Institute of Oceanography, State Oceanic Administration, Qingdao 266061, China

Received March 23, 2011; accepted April 8, 2011; published online May 12, 2011

\begin{abstract}
Japan suffered a M9.0 earthquake and massive tsunami on March 11, 2011, which seriously damaged the Fukushima Nuclear Power Plant and caused a nuclear crisis. The spread of nuclear radiation from the power plant through the atmosphere and ocean was predicted with a short-term climate forecasting model and an ocean circulation model under some idealized assumptions. If nuclear matter were leaked in the near-ground layer of $992 \mathrm{hPa}$, the climate model results show that the nuclear radiation would cover North America 10 days after the initial leakage, with the concentration at the forefront dramatically reduced to 10 millionths of the initial model concentration at the source. The radiation would span Europe in 15 days and cover much of the Northern Hemisphere in 30 days. If the initial leakage was assumed to occur in the layer 5000-m above the ground, the radiation would cover Europe in 10 days and cover much of the Northern Hemisphere in 15 days. Moreover, under the assumption that the nuclear matter leaked in the 10000-m layer, the radiation would affect much of China after 10 days. The ocean circulation model indicates that the nuclear material would be slowly transported northeast of Fukushima and reach $150^{\circ} \mathrm{E}$ in 50 days, and the nuclear debris in the ocean would be confined to a narrow band. Compared with the spread in the ocean, the area affected by leaked nuclear radiation in the atmosphere would be very large. Atmospheric monitors in North America and Europe will be helpful for estimating the effect in China of any leaked nuclear material.
\end{abstract}

leaked nuclear material, spread, atmospheric and oceanic channels, prediction, numerical model

Citation: Qiao F L, Wang G S, Zhao W, et al. Predicting the spread of nuclear radiation from the damaged Fukushima Nuclear Power Plant. Chinese Sci Bull, 2011, 56: 1890-1896, doi: 10.1007/s11434-011-4513-0

There was a $M 9.0$ earthquake at 05:46 UTC on March 11, 2011 , centered at $\left(38.0^{\circ} \mathrm{N}, 142.9^{\circ} \mathrm{E}\right), 130 \mathrm{~km}$ from Sendai, Japan. A subsequent massive tsunami soon hit the eastern coastline of Japan. The Fukushima Nuclear Power Plant was severely damaged by the earthquake and tsunami and began leaking nuclear radioactive material into the atmosphere on March 12. The situation is still not under control at the time of writing.

It is necessary to track the spread of the leaked nuclear radiation since it will be transported and diffused in the atmosphere and ocean. To predict the long-distance spread of nuclear materials, the operational global forecasting system

*Corresponding author (email: qiaofl@ fio.org.cn) of the atmospheric environment was established in the late 1990s by the National Meteorological Center of China, which also set up a regional emergency response system in 2007 [1]. It is also necessary to predict the spread of nuclear material leaked from the damaged Fukushima Nuclear Power Plant using a short-term climate forecasting model and an ocean circulation model.

Generally speaking, there are three channels for transporting and diffusing leaked nuclear material: a fast channel by atmospheric circulation, a slow channel through ocean surface circulation, and an extremely slow channel through thermohaline circulation into the interior ocean at depth. In addition, the leaked nuclear material can also be transported by human activity, such as the movements of ships and planes. However, transportation through human activity is 
believed to be insignificant compared with transportation through atmospheric and oceanic circulations.

Climate and ocean models are useful in quantitatively estimating the spread of leaked nuclear material. Many organizations and institutes have carried out synoptic-scale simulations and predictions of the nuclear radiation leaked from the Fukushima Nuclear Power Plant; such as the Comprehensive Nuclear Test Ban Treaty Organization (http://www.nytimes.com/interactive/2011/03/16/science/plume-graphic.html?ref=science), Belgian Institute for Space Aeronomy (http://aeronomie.be/multimedia/video/daiichi3washout_bira-iasb_animated.gif), Finnish Meteorological Institute (http://en.ilmatieteenlaitos.fi/japan), Norwegian Institute for Air Research (http://transport.nilu.no/products/fukushima), University of Maryland (http://209.157.64.200/focus/f-news/ 2692551/posts), and International Atomic Energy Agency (http://blog.alexanderhiggins.com/net2/japan-nuclear-plumeradiation-map.aspx).

These simulations, however, only describe the spread of nuclear radiation in the atmosphere within a few days. We believe that prediction of the spread of nuclear radiation in the atmosphere and ocean over a much longer period with the help of climate and ocean models is much needed, although short-term climate forecasting is still in its infancy [2]. The National Center for Atmospheric Research (NCAR) climate forecasting model CCSM3 [3-7], widely used by climate researchers, has proven to be one of the best models in CMIP3 experiments [8]. Although there are common problems of tropical biases in the climate models [3,9], surface wave-induced mixing [10] was introduced in the model to improve the simulation of the Pacific surface temperature [11] and promote the predictability of short-term oceanic phenomena, such as an El Nino event [12]. The developed CCSM3 was employed in this study to predict the atmospheric environment from March 14 to June 13, which is further used to estimate the spread of leaked nuclear material in the atmosphere and to provide forcing terms for the ocean model.

MASNUM, a coupled wave-tide-circulation model, is used to simulate the spread of leaked nuclear radiation in the ocean. Surface wave-induced mixing [10] is used in the coupled model, which evidently improves the simulation of upper thermal structures and circulations in the global ocean and marginal seas [13-15]. Results show that the coupled model satisfactorily simulates and predicts various oceanic processes, such as summertime upwelling in the Yellow Sea [13], the dynamical relation between current convergence (divergence) and sunken macroalgae in the coastal area of Qingdao in 2008 [16], and the successful prediction of drifting trend of floating macroalgae in the Yellow Sea during 2010 [17].

The Kuroshio and Oyashio convergence zones in the northwestern Pacific are an important source of mode water in the western Pacific [18] since surface water in this area subducts in winter. The mode water subducts to a depth of about $300 \mathrm{~m}$ and is then transported in the ocean interior.
However, the transport is so slow that it takes about 12 years for the mode water to approach the area east of Taiwan Island [19]. It is unlikely that surface water with leaked nuclear materials subducts to such depth because March is not the favored season for mode water formation. Moreover, the transport would be extremely slow even if there was some subduction of nuclear radiation. Therefore, this paper mainly predicts transport on the basis of atmosphere and ocean surface circulations.

Models and numerical experiments are introduced in section 1. The simulated spread of leaked nuclear material in the atmosphere and ocean is presented in section 2. Discussion and summary are given in section 3 .

\section{Numerical models and their linkages}

\subsection{Climate model and numerical experiments}

The CCSM3 climate model [12] provided by the NCAR, USA, is used to predict the spread of the leaked nuclear material in the atmosphere. The atmospheric component of CCSM3 is CAM3.0 (Community Atmosphere Model Version 3.0) [4], with a horizontal resolution of T42 (about $2.8^{\circ}$ $\times 2.8^{\circ}$ ) and 26 vertical layers. It has been shown that CAM3.0 simulates the East Asian Monsoon fairly well [20].

The model is run for 300 years, and the globally averaged upper-ocean kinetic energy demonstrates that the model has achieved a quasi-stationary state by then. The Reynolds daily sea surface temperature [21] is assimilated into the climate model [12] from January 1, 1982, to March 14, 2011. The climate model is then integrated to provide a 3-month prediction from March 14, 2011, and to simulate the spread of the nuclear radiation. To idealize the nuclear leak in the climate model, we assume that the nuclear material was all released at once from one model grid near Fukushima on March 14, and the released nuclear concentration was 1.0 at the source. The numerical experiments are carried out under idealized cases that the nuclear material was leaked in the near-ground layer (992 hPa), 5000-m layer, or 10000-m layer. The embedded tracer model [4] of CAM3.0 is employed to predict the spread of leaked nuclear radiation regardless of its potential sinking in the atmosphere or other physical processes such as radiative decay. The mean concentration is obtained by integrating the radiation concentration through the whole atmospheric column. One tenth of the maximum column-averaged concentration at a given time is selected to denote the spread of the assumed nuclear material.

Two additional idealized experiments under assumptions that the nuclear radiation was leaked on January 14 or February 14 are designed to estimate the influence of atmospheric conditions on the spread of nuclear radiation.

\subsection{Ocean model and numerical experiments}

Operational MASNUM, a coupled wave-tide-circulation 
model [22], is used to predict the path of nuclear materials in the ocean under the assumption that the nuclear debris that leaked from the Fukushima Nuclear Power Plant entered the ocean slowly in the nearest coastal water. The Princeton Ocean Model $[23,24]$ is used as the ocean circulation model, and MASNUM-WAM $[25,26]$ is used as the ocean wave model. The operational system covers the Northwest Pacific Ocean $\left(0^{\circ}-50^{\circ} \mathrm{N}, 99^{\circ} \mathrm{E}-150^{\circ} \mathrm{E}\right)$ with a horizontal resolution of $(1 / 8)^{\circ} \times(1 / 8)^{\circ}$ and 21 sigma layers in the vertical. Open boundary conditions are provided by a global model [24] with a horizontal resolution of $(1 / 2)^{\circ} \times$ $(1 / 2)^{\circ}$. Atmospheric forcing before March 14, 2011, is obtained from NCEP/NCAR reanalysis data, and the forcing after March 14 is provided by the modified CCSM3 climate model (see section 1.1). It is seen that the switch in atmospheric forcing on March 14 is sufficiently smooth, having no apparent impact on the ocean model results. The concentration of the nuclear materials at the source is assumed to be constant during the whole simulation since the leaked nuclear material is assumed to enter the ocean slowly. Decaying and sinking processes of nuclear radiation are ignored in the ocean simulations.

Two additional idealized experiments under the assumptions that the nuclear radiation first entered the coastal water on January 14 or February 14 are carried out to estimate the influence of oceanic circulation on the spread of nuclear radiation.

\section{Model results}

\subsection{Spread of leaked nuclear materials via the atmos- pheric channel}

Averaged atmospheric circulation in the near-ground layer $(992 \mathrm{hPa})$ over the period from March 14 to April 14 is illustrated in Figure 1. The figure shows that the atmospheric circulation near Fukushima is controlled by the West Pacific subtropical high, and a southwesterly with a speed of 5-8 $\mathrm{m} / \mathrm{s}$ dominates the near-ground layer. The wind speed increases with altitude, even exceeding $30 \mathrm{~m} / \mathrm{s}$ at the top of the troposphere.

Figure 2 shows the time evolution of the simulated spread of leaked nuclear radiation in the atmosphere. If the nuclear materials were leaked within one grid of the near-ground layer of $992 \mathrm{hPa}$ (Figure 2(a)), the radiation would cover the northern part of Japan 3 days after the initial leakage. The majority of the nuclear radiation would extend northeastward and approach Bering Strait in the following 2 days. The nuclear radiation would cross the Pacific Ocean and North America, and affect Europe 15 days after the initial leakage. However, the model concentration of nuclear material at the forefront is only about $3 \times 10^{-6}$, in the order of 10 millionths of the initial model concentration at the source. The nuclear radiation would arrive in China within the next 5 days and cover much of the Northern Hemisphere in another 10 days. Supposing that the nuclear radiation material entered the 5000-m layer of the climate model (Figure 2(b)), the spread would affect North America in 5 days, cover Europe in another 5 days, and cover much of the Northern Hemisphere 5 days later. If the nuclear material was leaked in the 10000-m layer (Figure 2(c)), the spread would be even faster; it takes only 10 days for the radiation to span the majority of China.

It is worth noting that the leaked radiation may never enter the 5000-m or 10000-m layer. However, even if the nuclear material was leaked in the near-ground layer, the model results show that the spread in the atmosphere is fast and broad and the concentration decreases quickly.

\subsection{Spread of leaked nuclear materials via the oceanic channel}

Figure 3 shows the simulated spread of nuclear debris in the ocean 50 days after March 14, 2011. The arrows denote the

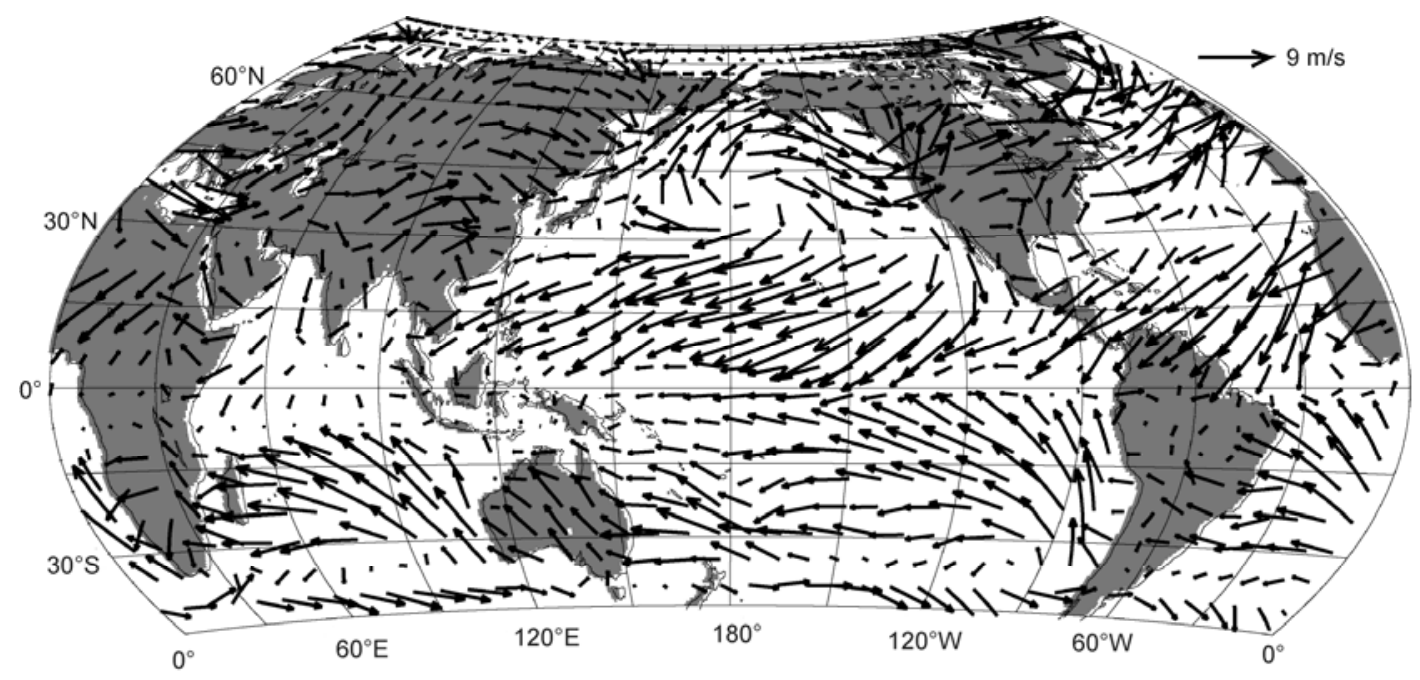

Figure 1 Predicted atmospheric circulation in the near-ground layer (992 hPa) averaged over the period from March 14 to April $14,2011$. 

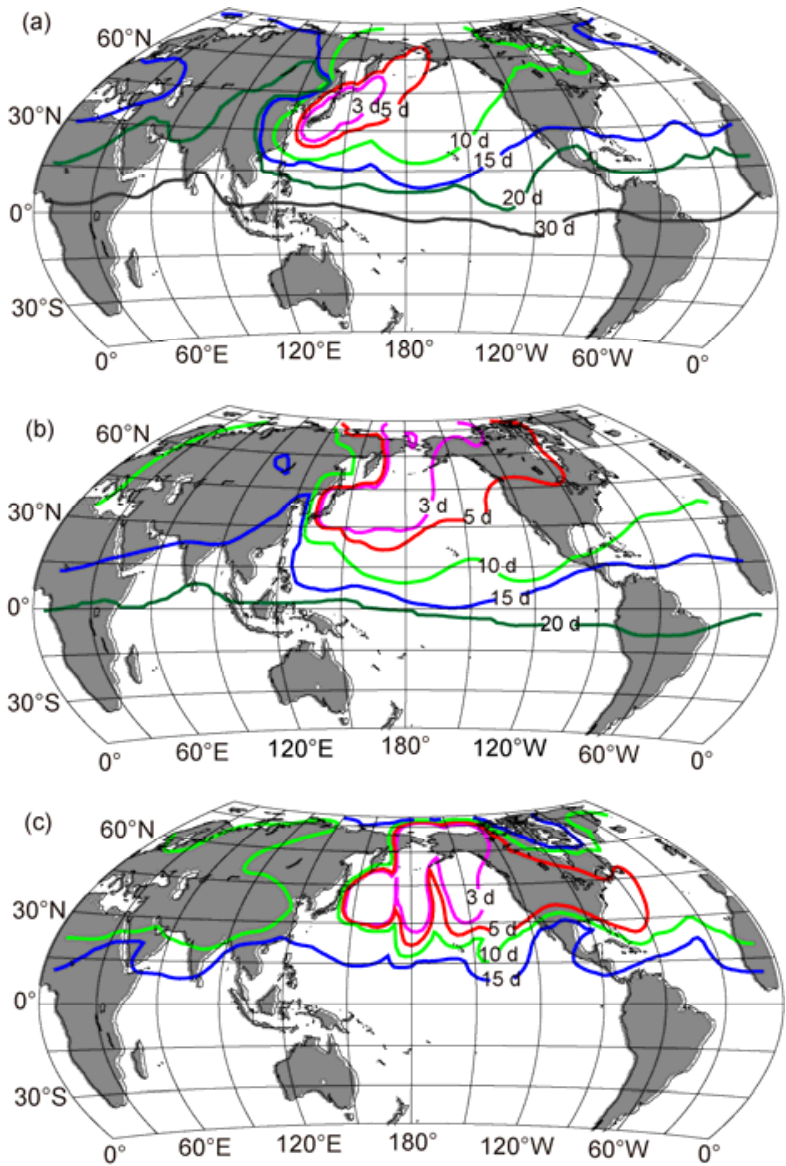

Figure 2 Predicted spread of the leaked nuclear radiation in the atmosphere under the assumption that the nuclear material was all released at once from one model grid near Fukushima in the near-ground layer (a), 5000-m layer (b), or 10000-m layer (c). A concentration of nuclear radiation of 1.0 is set at the source. The contours with the vertically averaged concentration equal to $10 \%$ of the maximum averaged concentration at various times are drawn to denote the spread of nuclear material. Purple, red, green, blue, dark-green, and black curves correspond to days $3,5,10$, 15,20 , and 30 , respectively, after the release. The concentrations corresponding to differently colored curves in (a) are $1 \times 10^{-4}, 5 \times 10^{-5}, 1 \times 10^{-5}$, $3 \times 10^{-6}, 2 \times 10^{-6}$, and $1 \times 10^{-6}$. For (b) and (c), the concentrations of $1 \times$ $10^{-4}, 5 \times 10^{-5}, 2 \times 10^{-5}, 7 \times 10^{-6}$, and $5 \times 10^{-6}$ correspond to days $3,5,10$, 15 , and 20 days, respectively.

mean circulation with current speeds higher than $0.2 \mathrm{~m} / \mathrm{s}$. The red curve represents the spread of the nuclear debris, with a contour value of 0.001 , one thousandth of the nuclear radiation concentration set at the source. The nuclear debris would be transported northward by the ocean currents initially, approach $38.5^{\circ} \mathrm{N}$, and turn eastward 20 days later. Fifty days after March 14, the nuclear debris would approach $150^{\circ} \mathrm{E}$, far from Chinese coastal waters. The nuclear debris in the ocean would be confined to a narrow band and the transportation of the leaked nuclear material in the ocean would be much slower than that in the atmosphere.

\subsection{Results of idealized numerical experiments}

On the basis of the CCSM3 climate model, two additional idealized experiments under assumption that the nuclear radiation was leaked on January 14 or February 14 are designed to examine the effect of atmospheric circulation on the spread of nuclear radiation. The nuclear materials were assumed to have been leaked at the near-ground layer of $992 \mathrm{hPa}$ in both experiments. Both idealized experiments (Figure 4) show that if the nuclear material was leaked on January 14 or February 14, the transport of nuclear radiation in the atmosphere would be faster than that of nuclear radiation leaked on March 14. The nuclear radiation would cover much of the zonal belt in 20 days for the both idealized experiments.

Figure 5 presents the simulation results for two idealized experiments using MASNUM, a coupled ocean model, where red, blue, purple, and black lines denote the spread of leaked nuclear material in the ocean 10,20,30, and 40 days after the initial leakage, respectively. If the nuclear materials were leaked on January (February) 14, the radiation would approach $150^{\circ} \mathrm{E}$ in 30 (40) days, which is 20 (10) days earlier than the case for leaking on March 14. This implies that the specific surface ocean circulation affects the spread of leaked nuclear radiation in the ocean.

\section{Discussion and summary}

The M9.0 earthquake and massive tsunami occurring on March 11, 2011, seriously damaged the Fukushima Nuclear Power Plant in Japan and caused a nuclear crisis that, almost a month later, is yet not to be fully controlled. The modified CCSM3 climate model and MASNUM coupled wave-tide-circulation model were used to make 3-month predictions of atmospheric and oceanic circulations and the spread of leaked nuclear radiation.

Several assumptions were made. The leaked nuclear radiation material is assumed to be transported and to diffuse with wind and ocean currents without considering sinking or radiative decay. The source of leaked nuclear material is idealized as a unit concentration within one grid in the atmosphere or ocean model. The climate and ocean models provide only the "contaminated" areas but not actual concentrations of the leaked nuclear radiation; in fact, the radiation concentration will decrease dramatically with distance from the source. The effects of nuclear material leaked to a higher altitude were also tested; however, it is still not yet clear whether the leaked nuclear matter can attain such altitudes.

There are always errors and biases in climate and ocean models. The errors and biases may accumulate with prediction time, leading to greater errors in the prediction of the spread of radiation.

Under the above assumptions, 3-month predictions of the spread of leaked radiation were performed in this study. Additional idealized numerical simulations were carried out with the nuclear material assumed to have been leaked 

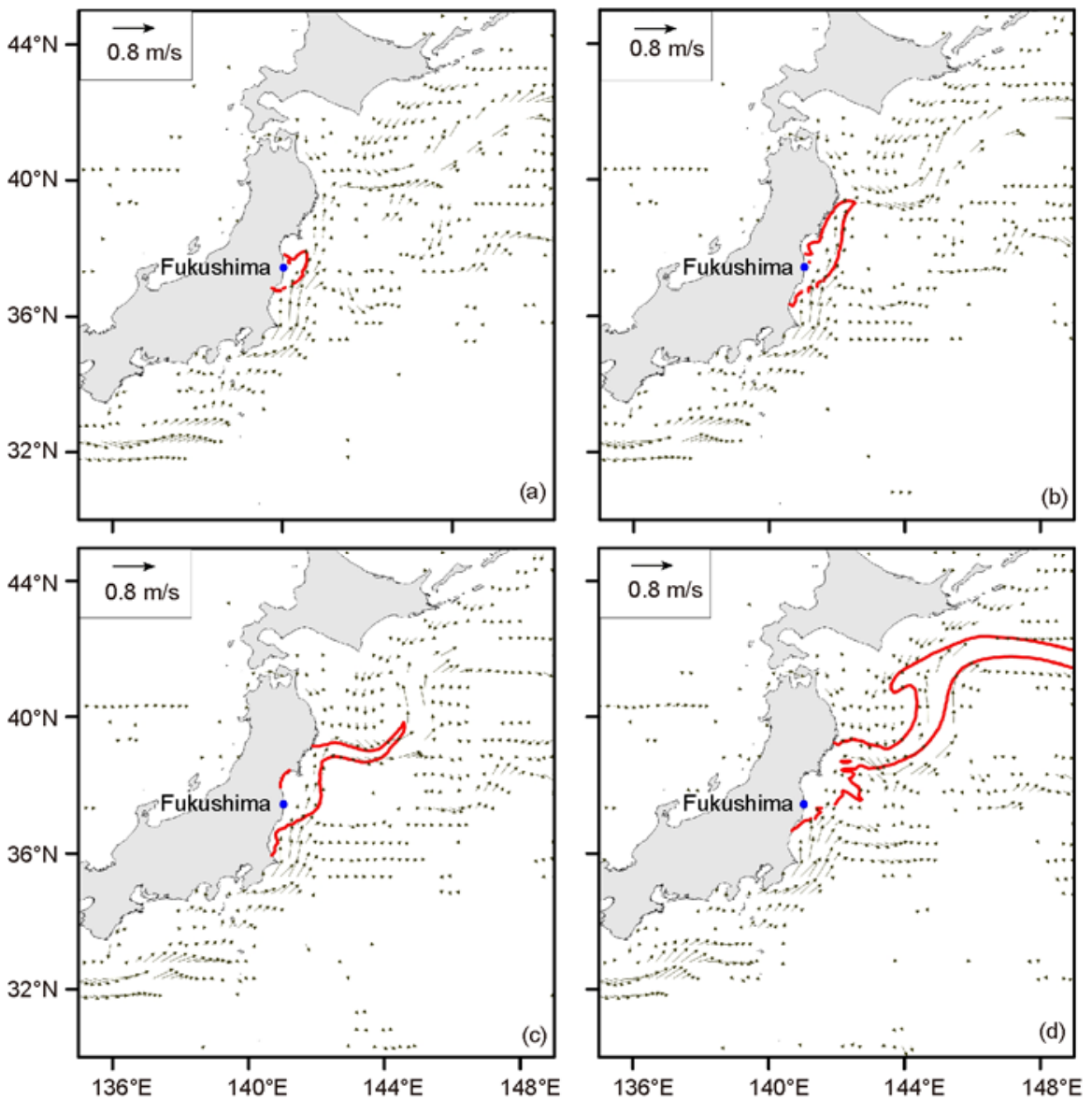

Figure 3 Predicted ocean surface currents (vector) and the spread of leaked nuclear radiation debris in the ocean (red line, with a contour value of 0.001 ) while the nuclear radiation concentration is set at 1.0 at the source. (a), (b), (c) and (d) are for days 10, 20, 30, and 50 after the initial leakage, respectively.
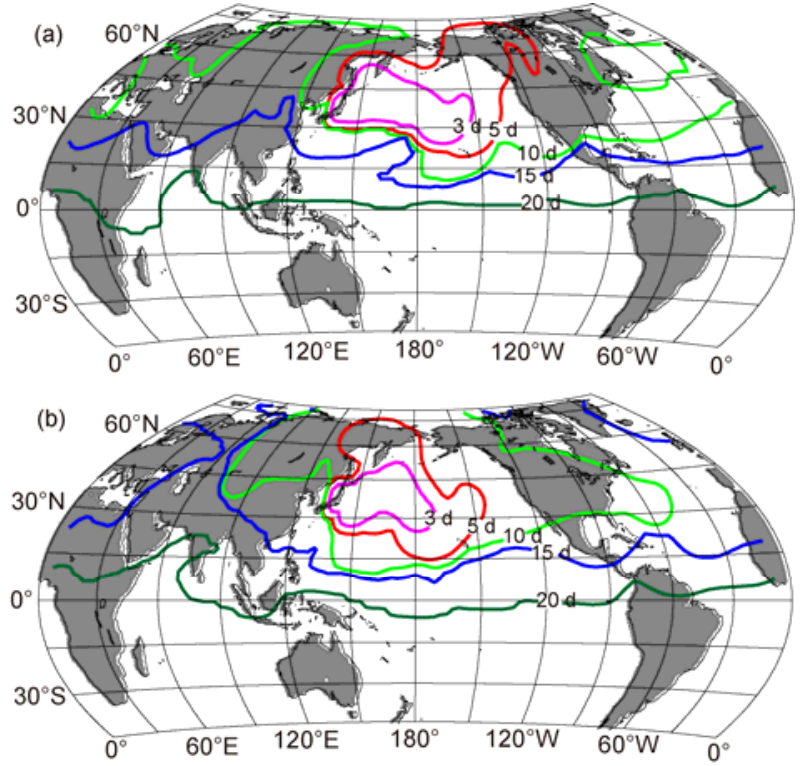

Figure 4 Predicted spread of nuclear material in the atmosphere under the assumption that the nuclear radiation was leaked on January 14, 2011 (a), or February 14, 2011 (b). A nuclear-radiation concentration of 1.0 is set at the model grid in the near-ground layer ( $992 \mathrm{hPa})$ near Fukushima. The concentrations of $3 \times 10^{-5}, 1 \times 10^{-5}, 5 \times 10^{-6}, 3 \times 10^{-6}$, and $1 \times 10^{-6}$ correspond to days $3,5,10,15$, and 20 , respectively.
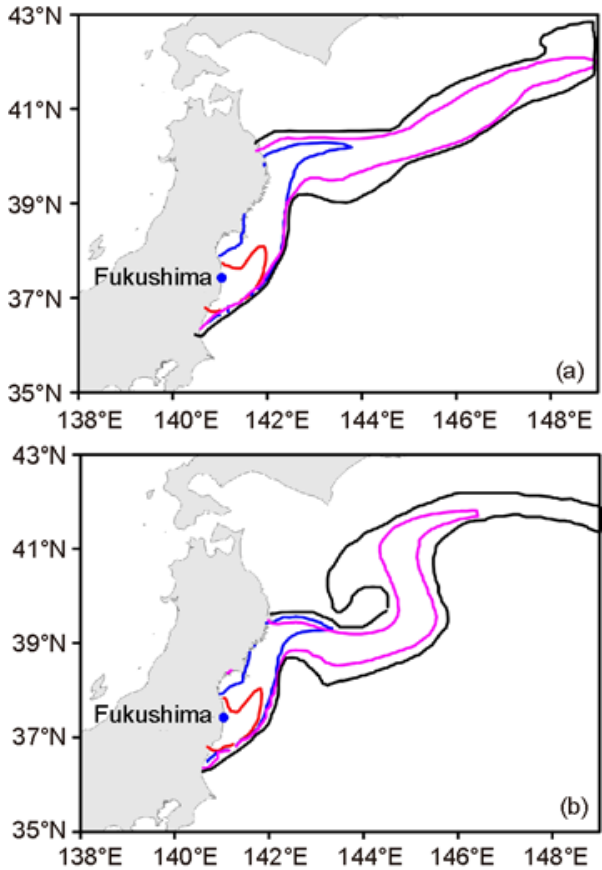

Figure 5 Predicted spread of nuclear material in the ocean under the assumption that the nuclear radiation was leaked on January 14, 2011 (a), or February 14, 2011 (b). Red, blue, purple, and black curves denote the spread on days $10,20,30$, and 40 after the initial leakage, respectively. 
at different times. Model results are summarized as follows.

Spread via the atmospheric channel. If the nuclear material was leaked in the near-ground layer of $992 \mathrm{hPa}$, the radiation would cover North America in 10 days while the model concentration of nuclear material at the forefront would be dramatically reduced to about 10 millionths of the initial concentration at the source. The nuclear radiation would cross Europe and the front would arrive in China within the next 10 days, and cover much of the Northern Hemisphere in another 10 days. Supposing that the nuclear radioactive material entered the 5000-m layer of the climate model, the spread of leaked nuclear material would cover Europe within 10 days, and cover much of the Northern Hemisphere 15 days after the initial leakage. If the nuclear material was leaked into the 10000-m layer, the spread would be even faster; it would take only 10 days for the radiation to span North America and Europe, and then affect the majority of China.

Spread via the oceanic surface channel. If the nuclear material entered the ocean, it would be slowly transported toward the northeast and reach $150^{\circ} \mathrm{E}$ after 50 days, but the nuclear debris would be confined to a narrow band.

Idealized numerical experiments. If the nuclear radiation was assumed to have been leaked on January 14 or February 14 , the transport of nuclear material in both the atmosphere and ocean would be faster than the transport of nuclear material that was leaked on March 14.

Radiation monitors are needed in China, and atmospheric monitors in North America and Europe will be helpful in estimating the effects of leaked nuclear material in China. Leaked nuclear material sinks and decays in reality, and thus, the concentration would be less than that predicted here when the nuclear radiation reached China. The Comprehensive Nuclear-Test-Ban Treaty Organization reported the monitoring of radioactive materials from Japan on its website on April 7, 2011 (http://www.ctbto.org/press-centre/ highlights/2011/fukushima-related-measurements-by-thectbto/fukushima-related-measurements-by-the-ctbto-page-1/). The Takasaki monitoring station, about 300 kilometers from the Fukushima Nuclear Power Plant, first detected radioactive isotopes on March 12. Radioactive isotopes were detected in eastern Russia on March 14 and approached the west coast of the United States 2 days later. The radioactive materials crossed North America 9 days after the accident. Three days later, a station in Iceland detected radioactive materials, which indicated that the leaked nuclear material had affected Europe. Radioactive material from Fukushima was detectable in almost the entire Northern Hemisphere 15 days after the initial leakage. Meanwhile, the monitoring results recorded up to April 7 showed that the radioactive levels outside Japan were far below the levels that could harm human health and the ecological environment. The monitoring results are generally consistent with the predictions made in this study.

More studies need to be carried out to quantitatively im- prove the predictions made in this study. First, the horizontal resolution of the tracer model in the global climate model is about $2.8^{\circ} \times 2.8^{\circ}$, which may lead to overestimation of the diffusion of nuclear material in the atmosphere. A high-resolution model will be helpful to reproduce actual processes; however, this requires more computing power. Second, $992 \mathrm{hPa}$ is the nearest ground layer of the climate model. The rate of spread should be lower than that predicted if the nuclear material was actually leaked in a layer lower than $992 \mathrm{hPa}$. Third, diffusivity of the general tracer in the atmosphere was chosen for horizontal diffusion of leaked nuclear material, which may also introduce error. Finally, it is much better to use the actual amount of leakage from Fukushima during the simulation, while because of a lack of data only unit concentration at one model grid was used in this study to idealize the actual nuclear leakage. There are many assumptions built into these predictions, and therefore, all our predictions need to be verified with more data over a longer timeframe. Even so, we believe that the general transport paths and the spread of leaked nuclear material presented here provide useful information for further research.

We greatly appreciate the advice given by Professor Wu Guoxiong at the Institute of Atmospheric Physics of the Chinese Academy of Sciences. This work was supported by the National Basic Research Program of China (2010CB950303) and the National Natural Science Foundation of China (40730842).

1 Sun M H, Song Z X, Lü D L, et al. Numerical prediction system of regional atmospheric environmental emergency response (in Chinese). Meteorol Sci Tech, 2010, 38: 635-641

2 Chou J F, Xu M. Advancement and prospect of short-term Numerical climate prediction (in Chinese). Chinese Sci Bull, 2001, 46: 890-895

3 Collins W D, Bitz C M, Blackmon M L, et al. The community climate system model: CCSM3. J Clim, 2006, 19: 2122-2143

4 Collins W D, Rasch P J, Boville B A, et al. The Formulation and Atmospheric Simulation of the Community Atmosphere Model Version 3 (CAM3). J Clim, 2006, 19: 2144-2161

5 Dickinson R E, Oleson K W, Bonan G, et al. The Community Land Model and its climate statistics as a component of the Community Climate System Model. J Clim, 2006, 19: 2302-2324

6 Briegleb B P, Bitz C M, Hunke E C, et al. Scientific description of the sea ice component in the Community Climate System Model, Version Three. Technical Report NCAR/TN-463+STR. 2004

7 Simith R D, Gent P R. Reference manual for the Parallel Ocean Program (POP), ocean component of the Community Climate System Model (CCSM2.0 and 3.0). Technical Report LA-UR-02-2484. 2002

8 Zhou T J, Yu R C. Twentieth century surface air temperature over China and the globe simulated by coupled climate models. J Clim, 2006, 19: 5843-5858

9 Davey M, Huddleston M, Sperber K, et al. STOIC: a study of coupled model climatology and variability in tropical ocean regions. Clim Dyn, 2002, 18: 403-420

10 Qiao F L, Yuan Y L, Yang Y Z, et al. Wave-induced mixing in the upper ocean: Distribution and application to a global ocean circulation model. Geophys Res Lett, 2004, 31: L11303, doi: 10.1029/ 2004 GL019824

11 Song Z Y, Qiao F L, Wang C Z. The correctness to the spuriously simulated semi-annual cycle of the sea surface temperature in the equatorial eastern Pacific. Sci China Erath Sci, 2011, 54: 438-444

12 Song Z Y, Qiao F L, Zhao W. The improvement on prediction ability 
of climate model CCSM3 (in Chinese). Prog Nat Sci, 2009, 19: 203211

13 Xia C S, Qiao F L, Yang Y Z, et al. Three-dimensional structure of the summertime circulation in the Yellow Sea from a wave-tidecirculation coupled model. J Geophys Res, 2006, 111: C11S03, doi:10.1029/2005JC003218

14 Lü X G, Qiao F L, Wang G S, et al. Upwelling off the west coast of Hainan Island in summer: Its detection and mechanisms. Geophys Res Lett, 2008, 35: L02604, doi:10.1029/2007GL032440

15 Qiao F L, Yuan Y L, Ezer T, et al. A three-dimensional surface waveocean circulation coupled model and its initial testing. Ocean Dyn, 2010, 60: 1339-1355

16 Lü X G, Qiao F L. Distribution of sunken macroalgae against the background of tidal circulation in the coastal waters of Qingdao, China, in summer 2008. Geophys Res Lett, 2008, 35: L23614, doi:10.1029/ 2008GL036084

17 Qiao F L, Wang G S, Lü X G, et al. Drift characteristics of the green macroalgae in the Yellow Sea in 2008 and 2010. Chinese Sci Bull, 2011, 56:

18 You Y, Suginohara N, Fukasawa M, et al. Transport of North Pacific Intermediate Water across Japanese WOCE sections. J Geophys Res, 2003, 108: 3196

19 Liu Q Y, Hu H B. A subsurface pathway for low potential vorticity transport from the central North Pacific toward Taiwan island. Ge- ophys Res Lett, 2007, 34: L12710, doi:10.1029/2007GL029510

20 Chen H M, Zhou T J, Neale R B, et al. Performance of the new NCAR CAM3.5 in East Asian summer Monsoon simulations: Sensitivity to modifications of the convection scheme. J Clim, 2010, 23: 3657-3675

21 Reynolds R W, Smith T M, Liu C, et al. Daily high-resolutionblended analyses for sea surface temperature. J Clim, 2007, 20: 54735496

22 Wang G S, Qiao F L, Xia C S. Parallelization of a coupled wave-circulation model and its application. Ocean Dyn, 2010, 60: 331-339

23 Blumberg A F, Mellor G L. A description of a three-dimensional coastal ocean circulation model. In: Heaps N S, ed. Three Dimensional Coastal Ocean Models, Vol 4. Washington D C: American Geophysical Union, 2010. 1-16

24 Xia C S, Qiao F L, Zhang Q H, et al. Numerical modeling of the quasiglobal ocean circulation based on POM. J Hydrodyn, 2004, 16: 537- 543

25 Yuan Y L, Pan Z D, Hua F, et al. LAGFD-WAM numerical wave model-I. Basic physical model. Acta Oceanol Sin, 1991, 10: 483488

26 Yang Y Z, Qiao F L, Zhao W, et al. MASNUM ocean wave numerical model in spherical coordinates and its application (in Chinese). Acta Oceanol Sin, 2005, 27: 1-7

Open Access This article is distributed under the terms of the Creative Commons Attribution License which permits any use, distribution, and reproduction in any medium, provided the original author(s) and source are credited. 